\title{
The finite element analysis of vacuum leak detection container
}

\author{
Donghui Meng ${ }^{a}$, Lichen Sun ${ }^{b}$, Jinming Chen, Rongping Shao, Xinfa Yu, \\ Xiaoyang Li, Haifeng Zhang, Yueshuai Zhao
}
Beijing Institute of Spacecraft environment engineering, Beijing, China
amengdonghui@126.com, bsunlichen-007@163.com,_

\begin{abstract}
Keywords: Vacuum leak detection container;The finite element analysis; Flange;External pressure Abstract. According to the requirement of vacuum leak detection container for small satellite, a set of vacuum leak detection container is developed. This paper discuss the design of model and the finite element analysis of different models. Through calculating the variation of the displacement $X$, $\mathrm{Y}, \mathrm{Z}$ of different parts of the door and the cabinet, the stress distribution of different parts and the rotation $\mathrm{Z}$ of the door flange and casing flange, we determine whether the deflection of flange under internal vacuum will cause the fall of the sealing effect of the sealing ring.
\end{abstract}

\section{Introduction}

The development of space industry enhances the requirement of the satellite on-orbit life and reliability unceasingly. Satellite leak detection performs as an important link in the course of the development of satellite, improving the reliability of leak detection is quite important ${ }^{[1]}$. In order to adapt to the demand of the small satellite leak detection task under the new situation, we developed a set of vacuum leak detection equipment, and in order to improve the reliability of the leak detection equipment, we make simulated analysis of the vacuum leak detection equipment.

\section{Model of the door and the cabinet}

We developed 3 types of model for the door and 5 types of model for the cabinet. The three-dimensional entity models of the door and the cabinet are shown in Fig. 1 and Fig. 2.

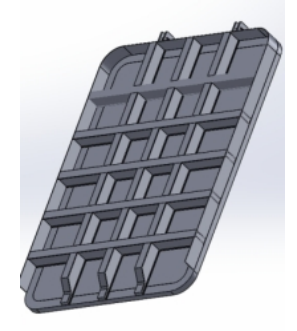

a) Flat gate 1

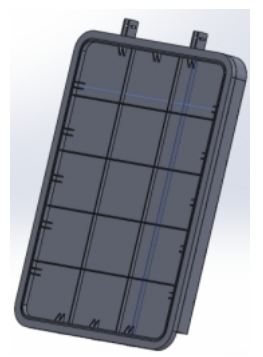

b) Flat gate 1

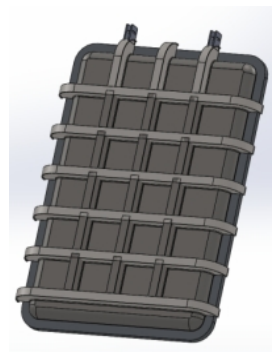

c) Convex door

Fig. 1 Three-dimensional entity model of the door 


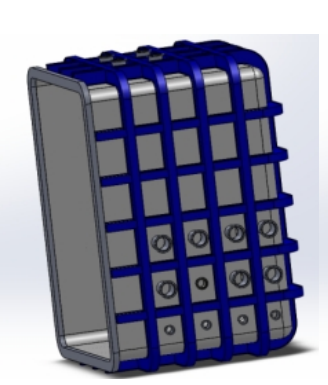

a) Model 1

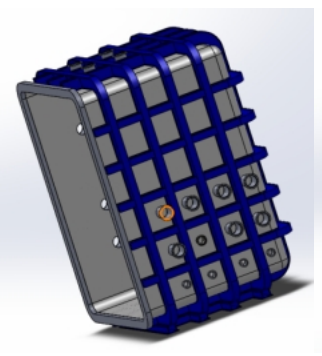

b) Model 2

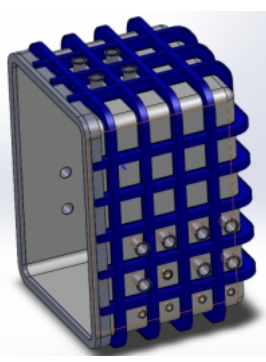

c) Model 3

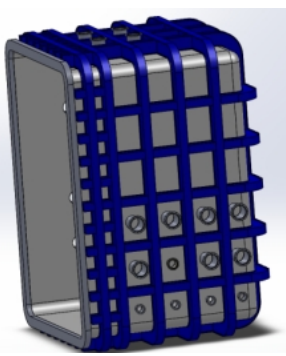

d) Model 4

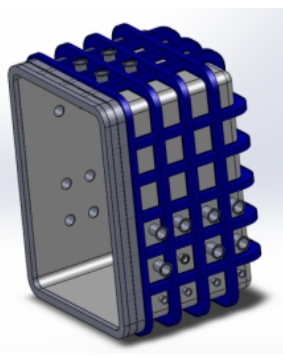

e) Model 5

Fig. 2 Three-dimensional entity model of the cabinet

\section{The simulation and analysis of the vacuum leak detection container}

\section{Finite element modeling}

Using the finite element analysis software Marc, we make the finite element model. The finite element model is shown in Fig. 3. The wall thickness of the container body is $24 \mathrm{~mm}$ while thickness of the stiffened panel is $20 \mathrm{~mm}$. Adding triangle stud inside of door to minimize the displacement of gate and stress when vacuum inside. The thickness of triangle stud is $40 \mathrm{~mm}$. Materials used in the vacuum leak detection container is stainless steel $0 \mathrm{Cr} 18 \mathrm{Ni} 9$ and carbon steel Q235A, material properties are shown in Table 1. All units are under gravity. The respective weight of DN1250, DN320 and DN500 is $3500 \mathrm{~kg}, 300 \mathrm{~kg}$ (single) and $300 \mathrm{~kg}$.

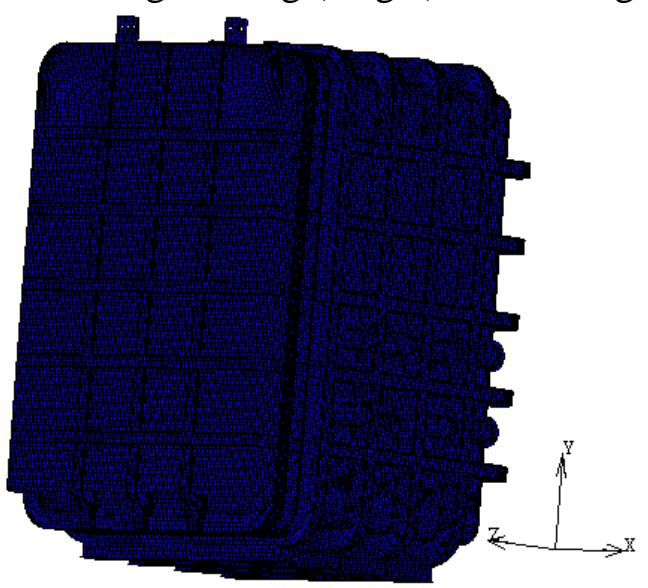

Fig. 3 The finite element model

Table 1 Material attribute set table

\begin{tabular}{ccccc}
\hline Material & $\begin{array}{c}\text { Young's modulus } \\
(\mathrm{MPa})\end{array}$ & $\begin{array}{c}\text { Poisson's } \\
\text { ratio }\end{array}$ & Density $\left(\mathrm{Kg} / \mathrm{m}^{3}\right)$ & $\begin{array}{c}\text { Yield stress } \\
(\mathrm{MPa})\end{array}$ \\
\hline 0Cr18Ni9 & 210000 & 0.3 & 7900 & 210 \\
Q235A & 210000 & 0.3 & 7500 & 235 \\
\hline
\end{tabular}

\section{Calculation and analysis of the results}

Load cases are mainly divided into two types, Condition one: Considering the weight of container and equipment only; Condition two: Considering the external load and the weight of container and equipment under the condition of vacuum, etc.

Making the finite element analysis and calculation of the door model and the cabinet model. 
Under a variety of boundary conditions, what we calculate includes the variation of the displacement $\mathrm{X}, \mathrm{Y}, \mathrm{Z}$ in different parts of door and the cabinet, the stress distribution in different parts and the rotation $\mathrm{Z}$ in door flange and casing flange, through which we can better determine whether the deflection of internal vacuum flange will cause the fall of the sealing effect of the sealing ring. Deformation and maximum stress situation of the door model and the cabinet model are shown in the following Table 2 and Table 3 respectively.

Table 2 Deformation and maximum stress situation of the different door model

\begin{tabular}{|c|c|c|c|c|c|c|}
\hline \multicolumn{2}{|c|}{ Model } & $\begin{array}{c}\text { Displacement } \\
\text { X (mm) }\end{array}$ & $\begin{array}{c}\text { Displacement } \\
\text { Y (mm) }\end{array}$ & $\begin{array}{c}\text { Displacement } \\
\text { Z }(\mathrm{mm})\end{array}$ & $\begin{array}{c}\text { Rotation Z } \\
\text { of the } \\
\text { flange } \\
(\mathrm{mm})\end{array}$ & $\begin{array}{c}\text { Maximum } \\
\text { equivalent } \\
\text { stress (MPa) }\end{array}$ \\
\hline \multirow{3}{*}{ Gate 1 } & L 1 & $\begin{array}{c}(-1.12 \sim 1.11)^{*} 1 \\
0^{-2}\end{array}$ & $-0.13 \sim 0$ & $-0.47 \sim 0$ & & 15.46 \\
\cline { 2 - 7 } & L 2 & $-0.63 \sim 0.52$ & $-0.52 \sim 0.58$ & $-3.41 \sim 0.37$ & 0.54 & 131 \\
\hline \multirow{2}{*}{ Gate 2 } & L 1 & $-0.007 \sim 0.007$ & $-0.05 \sim 0$ & $-0.01 \sim 0.27$ & & 19.3 \\
\cline { 2 - 8 } & L 2 & $-0.488 \sim 0.486$ & $-0.450 \sim 0.391$ & $-2.779 \sim 0.353$ & 0.45 & 107.3 \\
\hline \multirow{2}{*}{$\begin{array}{c}\text { Conve } \\
\text { x door }\end{array}$} & L 1 & $-0.028 \sim 0.011$ & $-0.19 \sim 0$ & $-0.09 \sim 0.66$ & & 13.5 \\
\cline { 2 - 8 } & L 2 & $-1.114 \sim 1.080$ & $-0.576 \sim 0.352$ & $-3.319 \sim 0.571$ & 0.72 & 100.5 \\
\hline
\end{tabular}

Table 3 Deformation and maximum stress situation of the cabinet model

\begin{tabular}{|c|c|c|c|c|c|c|}
\hline \multicolumn{2}{|c|}{ Model } & \multirow{2}{*}{$\begin{array}{c}\text { Displacemen } \\
\text { t X (mm) } \\
-0.23 \sim 0.21 \\
\end{array}$} & \multirow{2}{*}{$\begin{array}{c}\begin{array}{c}\text { Displaceme } \\
\text { nt Y (mm) }\end{array} \\
-0.35 \sim 0 \\
\end{array}$} & \multirow{2}{*}{$\begin{array}{l}\text { Displaceme } \\
\text { nt Z (mm) }\end{array}$} & \multirow{2}{*}{$\begin{array}{l}\text { Rotation } \mathrm{Z} \text { of } \\
\text { the } \\
\text { flange }(\mathrm{mm})\end{array}$} & \multirow{2}{*}{$\begin{array}{c}\begin{array}{c}\text { Maximum } \\
\text { equivalent } \\
\text { stress }(\mathrm{MPa})\end{array} \\
16.23 \\
\end{array}$} \\
\hline Mode & L 1 & & & & & \\
\hline $\begin{array}{l}1 \\
1\end{array}$ & L 2 & $-7.56 \sim 7.90$ & $-0.91 \sim 0.69$ & $-0.17 \sim 1.90$ & 0.4 & 131 \\
\hline \multirow{2}{*}{$\begin{array}{c}\text { Mode } \\
1 \\
2\end{array}$} & L 1 & $-0.24 \sim 0.20$ & $-0.36 \sim 0$ & $-0.24 \sim 0.18$ & & 14.98 \\
\hline & L 2 & $-7.39 \sim 7.72$ & $-1.14 \sim 1.29$ & $-1.24 \sim 1.17$ & 0.4 & 125.7 \\
\hline \multirow{2}{*}{$\begin{array}{l}\text { Mode } \\
1 \\
3\end{array}$} & L 1 & $-0.23 \sim 0.20$ & $-0.35 \sim 0$ & $-0.22 \sim 0.20$ & & 14.98 \\
\hline & L 2 & $-6.56 \sim 6.82$ & $-1.12 \sim 1.22$ & $-1.14 \sim 1.20$ & 0.32 & 133.5 \\
\hline \multirow{2}{*}{$\begin{array}{c}\text { Mode } \\
1 \\
4\end{array}$} & L 1 & $-0.23 \sim 0.21$ & $-0.31 \sim 0$ & $-0.10 \sim 0.15$ & & 18.55 \\
\hline & L 2 & $-5.02 \sim 5.28$ & $-0.96 \sim 0.65$ & $-0.27 \sim 1.83$ & 0.3 & 86.11 \\
\hline \multirow{2}{*}{$\begin{array}{c}\text { Mode } \\
1 \\
5\end{array}$} & L 1 & $-0.22 \sim 0.20$ & $-0.35 \sim 0$ & $-0.21 \sim 0.21$ & & 14.98 \\
\hline & L 2 & $-5.78 \sim 6.15$ & $-1.10 \sim 1.16$ & $-1.06 \sim 1.22$ & 0.41 & 131.3 \\
\hline
\end{tabular}

Analysis 1: As Table 2, for gate 1, only under the condition of weight, deformation are relatively small in all directions, the maximum equivalent stress appears in the lug, approximately $15 \mathrm{Mpa}$, far less than the safe strength of lug material, the displacement $\mathrm{Z}$ is larger for the center of gravity of the gate doesn't overlap with the lug center, which cause displacement Z; Under the condition of external pressure, the center of the door have a large displacement $\mathrm{Z}$, the door concaves 
inward about $3.4 \mathrm{~mm}$, the maximum stress is $131 \mathrm{Mpa}$, which appears in the triangle stud inside of the door. For the gate 2, only under the condition of weight ,the maximum equivalent stress appears in the lug, approximately $17.73 \mathrm{Mpa}$, far less than the safety strength of lug material; Under the condition of weight and external pressure, the door have a large displacement $\mathrm{Z}$, the maximum stress is $131 \mathrm{Mpa}$, which appears in the central reinforcement of the door. The rotation $\mathrm{Z}$ of the flange is $0.45 \mathrm{~mm}$ under the condition of external pressure. For the convex door, only under the condition of weight, deformation are relatively small in all directions, the maximum equivalent stress appears in the lug, approximately $15.21 \mathrm{Mpa}$, far less than the safety strength of lug material; Under the condition of weight and external pressure, the convex door have a large displacement $\mathrm{Z}$, the maximum stress is $100.5 \mathrm{Mpa}$, which appears in the central door, the rotation of the flange is $0.7 \mathrm{~mm}$.

Analysis 2: As Table 3, for the 5 types of cabinet model, only under the condition of load case one, the deformation of three direction, the maximum stress value and the maximum stress of parts are basically identical. The maximum stress appears in the stiffener at the top of the saddle, which are all Less than 20Mpa among 5 types of model. Under the condition of load case two, for the 5 types of cabinet model, the rotation $\mathrm{Z}$ of the flange have some certain differences, the largest rotation is $0.4 \mathrm{~mm}$; The main variation for displacement of five models is displacement $\mathrm{X}$, which appears in the middle of the large flange. Displacement $\mathrm{X}$ according to the order from large to small is model 1 , model 2, model 3, model 5 and model 4, this illustrates that the strengthening effect near the flange part of model 4 is better. In addition, from the maximum equivalent stress and the rotation $\mathrm{Z}$ of the flange, we can learn that both the maximum equivalent stress and the rotation $\mathrm{Z}$ of model 4 are minimal, and the strengthening effect of model 5 is the best.

\section{Nonlinear buckling analysis}

The geometric nonlinear finite element analysis can more accurately get the structure deformation and internal force distribution. Nonlinear buckling analysis is an important application of geometric nonlinear finite element analysis ${ }^{[2-4]}$.

\section{Nonlinear buckling analysis of door}

When making nonlinear buckling analysis of door, increasing the pressure on the door to $0.8 \mathrm{Mpa}$. For the main deformation is in $\mathrm{Z}$ direction, so we make analysis of displacement $\mathrm{Z}$ along with the change of external pressure. The relationship curve between displacement $Z$ and the external pressure is shown in Fig. 4a). When the external pressure is less than 0.5Mpa, the biggest displacement increases in linear growth trend basically. But when the external pressure exceeds $0.6 \mathrm{MPa}$, the displacement increases greatly along with the increase of external pressure. For gate, the critical load is between 0.5 and $0.6 \mathrm{MPa}$.

\section{Nonlinear buckling analysis of cabinet}

Making nonlinear buckling analysis of cabinet, we analyze the deformation of cabinet while increasing the pressure load on cabinet continually. From the analysis above, it is obvious that the deformation of cabinet is mainly concentrated in the $\mathrm{X}$ direction. The relationship curve between displacement $X$ and the external pressure as shown in Fig. 4 b). For the model, When the external pressure is less than $0.4 \mathrm{Mpa}$, the displacement $\mathrm{X}$ increases in linear growth trend basically. But when the external pressure of model 1,2 exceeds $0.4 \mathrm{MPa}$ and the external pressure of model 4,5 exceeds $0.5 \mathrm{MPa}$, the displacement increases greatly along with the increase of external pressure, the curve shows obvious nonlinear change. And for model 3, model is not convergence after external pressure exceeds $0.4 \mathrm{MPa}$, so the critical load is about $0.4 \mathrm{Mpa}$. 


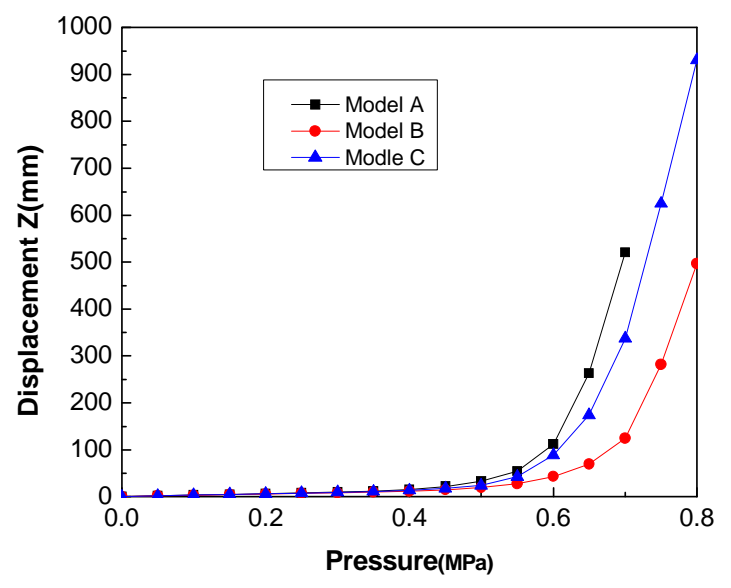

a) Displacement $\mathrm{Z}$ of door

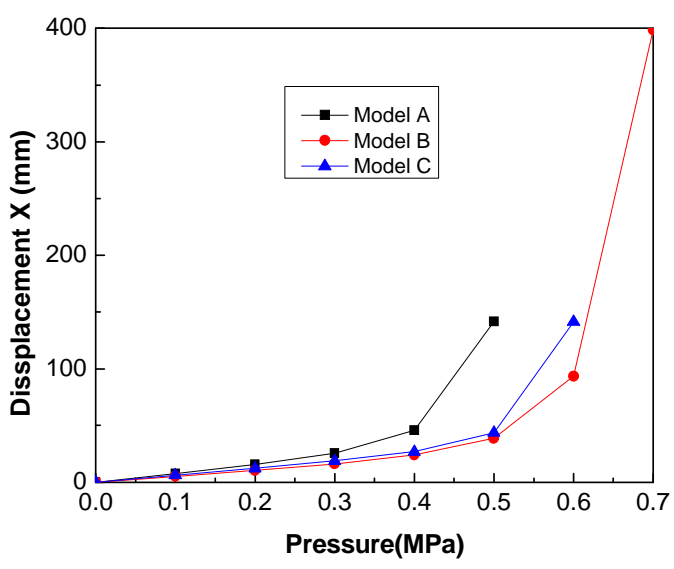

b) Displacement $\mathrm{X}$ of cabinet

Fig. 4 Relationship curve between displacement and the external pressure

\section{Conclusions}

In this essay, three types of door model and five types of cabinet model was proposed. The finite element simulation shows that:

The three types of door and the five types of cabinet satisfy the security strength;

For gate, the critical load is between 0.5 and $0.6 \mathrm{MPa}$, when the safety coefficient is 3 , the minimum critical load is $0.17 \mathrm{MPa}$;

For 5 types of cabinet, the critical load is between 0.4 and $0.5 \mathrm{MPa}$, the critical load of model 1-3 is about $0.4 \mathrm{Mpa}$ while $0.5 \mathrm{Mpa}$ for model $4 、 5$. when the safety coefficient is 3 , the critical load of model 5 is $0.13 \mathrm{Mpa}$, which is greater than atmospheric pressure $0.1 \mathrm{MPa}$ produced by vacuum.

\section{References}

[1] Q. Ding, W. Su, Y. Ge, et al: The Development of the Vacuum Leak Detection Equipment for Small Satellite. Spacecraft Environment Engineering, Vol. 23(2006), p. 169-174.

[2] D.S. Ling, X. Xu. Nonlinear finite element method and program. Hangzhou: Zhejiang university press, 2004:392.

[3] T.Y. Zheng, High analysis theory and practical calculation of steel structure. Beijing: Science press, 2007: 259.

[4] X.P. Shu, High steel structure design and analysis. Beijing: Science press, 2006: 331. 